\title{
Blood zinc in the spinal patient
}

\author{
R. G. BURR
}

From the National Spinal Injuries Centre, Stoke Mandeville Hospital, Aylesbury, Buckinghamshire

SYNOPSIS A rapid microspectrophotometric method was used to measure zinc concentrations in plasma and erythrocytes. A circadian variation in plasma zinc related to the ingestion of food was observed. Fasting plasma zinc concentrations were low in 20 out of 23 paraplegic patients with pressure sores, indicating that oral zinc supplementation may be expected to accelerate healing in such patients. Erythrocyte zinc levels did not differ between different groups of subjects and exhibited no circadian rhythm.

Oral zinc sulphate therapy increases the rate of healing of indolent ulcers when the serum zinc concentration before treatment is below $110 \mu \mathrm{g} /$ $100 \mathrm{ml}$ (Pories, Henzel, Rob, and Strain, 1967; Hallböok and Lanner, 1972). There is some doubt, however, about the need to give zinc supplements to patients with pressure sores. Brewer, Mihaldzic, and Dietz (1967) found that paraplegic patients with decubiti had normal levels of plasma zinc before treatment and did not benefit from zinc therapy, in contrast to the observations of Cohen (1968) and of Abbott, Exton-Smith, Millard, and Temperley (1968).

The older chemical methods for the measurement of zinc in biological specimens were tedious and time-consuming and required large volumes of sample. The advent of atomic absorption spectrophotometry, plastic laboratory ware, and automatic equipment for handling specimens and reagents has reduced the possibility of contamination and led to increased accuracy. In the present investigation, a recently published chemical method was used to assess the zinc status of paraplegic patients at this centre.

\section{Material}

The patients were divided into four groups consisting of 12 healthy control subjects ( 11 men and one woman, aged 19 to $38 \mathrm{yr}$ ); seven non-paraplegic patients (six male and one female, aged 37 to $68 \mathrm{yr}$ ) who had been admitted for a variety of plastic surgical procedures, and had received $220 \mathrm{mg}$ of zinc sulphate orally twice daily for at least 14 days; 14 male patients (aged 18 to $47 \mathrm{yr}$ ) with spinal cord Received for publication 16 July 1973. injury but without pressure sores who had been admitted for treatment of paraplegia and rehabilitation; and 23 paraplegic patients $(19$ men and four women, aged 20 to $67 \mathrm{yr}$ ) who had been admitted for treatment of pressure sores.

The circadian rhythm was studied by taking blood samples at $07.00,12.00,17.00$ and $22.00 \mathrm{hr}$ following normal hospital meals taken at 08.00 , 12.15 , and $18.00 \mathrm{hr}$ and light refreshment at 10.30, 15.30 , and 21.00 hours.

Venous blood was taken into lithium heparin, and plasma was separated within 30 minutes of collection. Haemolysed specimens were rejected.

\section{Methods}

Zinc concentrations in plasma $(2 \mathrm{ml})$ and in whole blood $(1 \mathrm{ml})$ were determined by a spectrophotometric method (Watkins, Weiner, and Zak, 1971). The haematocrit was measured using the Coulter counter model $\mathrm{S}$ and erythrocyte zinc concentrations were calculated using the formula

$$
Z_{n_{E}}=\frac{100}{H_{c t}}\left(Z_{n_{B}}-Z_{n_{P}}\right)+Z_{n_{P}}
$$

where $Z n_{B}, Z n_{P}$, and $Z n_{E}$ are the concentrations of zinc in whole blood, plasma, and erythrocytes respectively, and Hct is the haematocrit. Total plasma protein concentrations were measured using a biuret method (Varley, 1967).

\section{Results}

Figure 1 shows the means of the circadian variation of plasma zinc concentration in nine of the control subjects, 10 of the paraplegics without pressure 


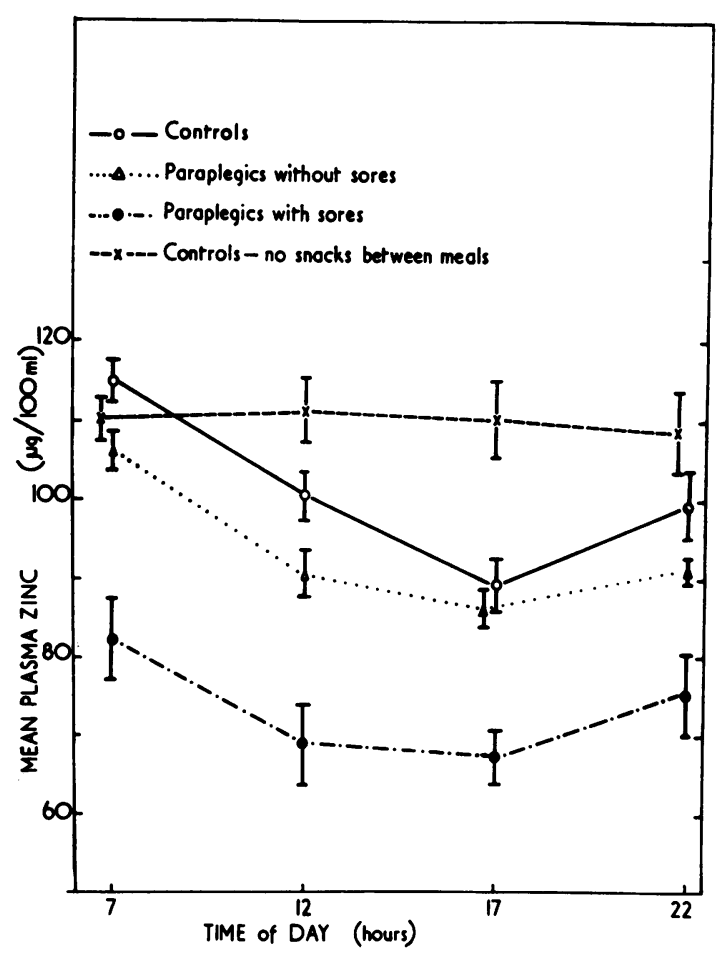

Fig 1 Circadian variation in plasma zinc concentrations. Nine healthy control subjects, 10 paraplegics without pressure sores, and 12 paraplegics with sores, eating three main meals per day and snacks between meals, compared with four control subjects eating three main meals but with morning coffee and afternoon tea omitted. Means \pm 1 standard error (SEM) are shown.

sores, and 12 of those with sores. This rhythm was demonstrable only when the subjects were eating both normal meals and snacks between meals. When morning coffee and afternoon tea were withheld, the variation was abolished (fig 1). It was concluded that to compare different groups of subjects blood should be taken either fasting or at least three hours after taking food or drink.

Figure 2 shows the fasting plasma zinc levels for the four groups of subjects studied. Every group differed significantly from each of the others $(P<0.001)$. The lower limit of normal was 105 $\mu \mathrm{g} / 100 \mathrm{ml}$ and $29(76 \%)$ of the 38 results for the patients with pressure sores were below this value. The plasma zinc concentration was below the limit of normal when first tested in 20 of the 23 patients, the subsequent values being obtained at monthly intervals.

The erythrocyte zinc concentrations were in the range $900-1500$ (mean 1195 ) $\mu \mathrm{g} / 100 \mathrm{ml}$ and were

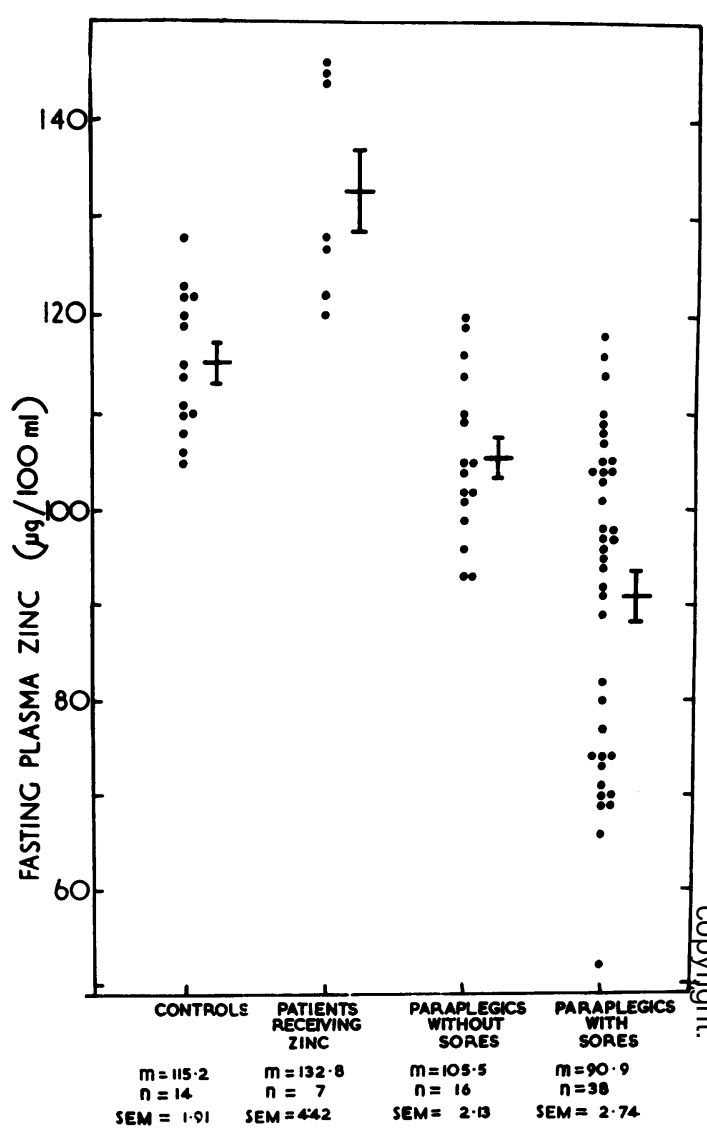

Fig 2 Fasting plasma zinc concentrations in 12 control subjects, in seven patients following zinc therapy, in 14 paraplegics without pressure sores, and in 23 paraplegics with sores. The blood samples were collected between 07.00 and 08.00 hours. Means \pm 1 SEM are shown.

not related to the time of day, to zinc therapy, to the presence of pressure sores, or to the plasma zinc levels. There was no correlation between the $\frac{\text { 의 }}{9}$ plasma levels of zinc and total protein.

\section{Discussion}

The method used to measure zinc was simple and $\tilde{N}$ rapid and did not require expensive instrumentation, $\underset{\omega}{N}$ but it was necessary to observe all the usual precautions recommended for trace-element analysis 0 (Thiers, 1957). Serum gave higher results than $\stackrel{\bar{\Phi}}{\circ}$ plasma, as previously reported by Foley, Johnson, $\stackrel{\infty}{+}$ Hackley, Smith, and Halsted (1968).

The mean plasma zinc concentration of the control subjects was lower than that of Hellwege 
(1970), but higher than those of other recent workers (Abbott et al, 1968; Davies, Musa, and Dormandy, 1968; Halsted and Smith, 1970); Meret and Henkin, 1971; Lindeman, Bottomley, Cornelison, and Jacobs, 1972) most of whom, however, did not detect any effect due to food. The lower limit of normal was close to that adopted by both Pories et al (1967) and Hallböök and Lanner (1972). Davies et al (1968) found that administration of glucose depressed plasma zinc levels for up to two hours, but stated that it was only necessary to allow one hour to elapse between food ingestion and blood collection. Hellwege (1970) observed a progressive fall during the day similar to that reported here. The present work shows in addition that the plasma zinc returns to the fasting level within three hours of taking food.

The paraplegic patients had significantly reduced plasma zinc concentrations, and the patients with sores had lower levels than those without. The concentration of zinc in plasma is known to be reduced by a variety of stresses, including surgery and acute infection (Lindeman et al, 1972; Beisel, Pekarek, Van Ormer, and Wannemacher, 1971), an effect which is mediated by a heat-labile protein of low molecular weight (Pekarek and Beisel, 1971). In addition, zinc is preferentially concentrated in healing tissue (Savlov, Strain, and Huegin, 1962). Zinc deficiency retards healing, and oral zinc sulphate therapy has been found to accelerate healing in patients with indolent ulcers who have low plasma zinc levels before treatment (Pories et al, 1967; Hallböök and Lanner, 1972). Bearing in mind the multiplicity of other factors which may delay the healing of decubitus ulcers, it is reasonable to expect that paraplegic patients with pressure sores and reduced plasma zinc levels will benefit from zinc supplementation.

Red blood cells contain a much higher concentration of zinc than plasma, suggesting that erythrocyte zinc may be a better index of body stores than plasma zinc. If so, the present results provide no evidence of zinc deficiency in the patients studied. It is more likely, however, that the zinc in erythrocytes is strongly bound, and is not readily depleted when the requirement for zinc increases.

I thank Mr B. N. Bailey for permission to study the patients in his care; Dr A. Barr for the statistical analyses; Wing-Cdr A. Broughton for his advice; Dr H. L. Frankel for suggesting the project; Dr C. S. Pitcher for the haematocrit determinations; Dr J. J. Walsh for his encouragement; Mr G. Wojniak for technical assistance; and the patients for their willing cooperation.

\section{References}

Abbott, D. F., Exton-Smith, A. N., Millard, P. H., and Temperley, J. M. (1968). Zinc sulphate and bedsores. Brit. med.J., 2, 763.

Beisel, W. R., Pekarek, R. S., Van Ormer, D., and Wannemacher, R. W. (1971). Influence of acute infection on the metabolism of zinc and other trace elements. Psychopharmacol. Bull., 34-35.

Brewer, R. D., Jr., Mihaldzic, N., and Dietz, A. (1967). The effect of oral zinc sulfate on the healing of decubitus ulcers in spinal cord injured patients In Proceedings of 16th Annual Clinical Spinal Cord Injury Conference, pp. 70-72. Veterans Administration Hospital, Long Beach, California.

Cohen, C. (1968) Zinc sulphate and bedsores. Brit. med. J. .2, 561.

Davies, I. J. T., Musa, M., and Dormandy, T. L. (1968). Measurements of plasma zinc. J. clin. Path., 21, 359-365.

Foley, B., Johnson, S. A., Hackley, B. M., Smith, J. C., Jr., and Halsted, J. A. (1968). Zinc content of human platelets. Proc. Soc. exp. Biol. (N.Y.), 128, 265-269

Hallböök T., and Lanner, E. (1972). Serum-zinc and healing of venous leg ulcers. Lancet, 2, 780-782.

Halsted, J. A., and Smith, J. C., Jr. (1970). Plasma zinc in health and disease. Lancet, 1, 322-324.

Hellwege, H. H. (1970). Tagesrhythmische Schwankungen des Serumzinkspiegels. Klin. Wschr., 48, 1063-1064.

Lindeman, R. D., Bottomley, R. G., Cornelison, R. L., Jr., and Jacobs, L. A. (1972). Influence of acute tissue injury on zinc metabolism in man. J. Lab. clin. Med., 79, 452-460.

Meret, S., and Henkin, R. I. (1971). Simultaneous direct estimation by atomic absorption spectrophotometry of copper and zinc in serum, urine and cerebrospinal fluid. Clin. Chem., 17, 369-373.

Pekarek, R. S., and Beisel, W. R. (1971). Characterization of the endogenous mediator(s) of serum zinc and iron depression during infection and other stresses. Proc. Soc. exp. Biol. (N.Y.), 138, 728-732.

Pories, W. J., Henzel, J. H., Rob, C. G., and Strain, W. H. (1967). Acceleration of healing with zinc sulfate. Ann. Surg., 165 , 432-436.

Savlov, E. D., Strain, W. H., and Huegin, F. (1962). Radiozinc studies in experimental wound healing. J. surg. Res., 2, 209-212.

Thiers, R. E. (1957). Contamination in trace element analysis and its control. Meth. biochem. Anal., 5, 273-335.

Varley, H. (1967). Practical Clinical Biochemistry, 4th. ed., p. 236. London, Heinemann.

Watkins, R., Weiner, L. M., and Zak, B. (1971). Determination of copper, iron and zinc from a single small sample. Microchem. J., 16, 14-23. 